\title{
Kultuurkritiek, eerste-eeuse kulturele wysheid en die alternatiewe visie van Jesus van Nasaret
}

\author{
Andries van Aarde \\ Departement Nuwe-Testamentiese Wetenskap (Afd A) \\ Universiteit van Pretoria
}

\begin{abstract}
Culture criticism, cultural wisdom in the first century and the alternative vision of Jesus of Nazareth

Culture criticism represents a critical position towards those culturally oriented studies which advocate a positivist subject-object schema in epistemology. In this kind of epistemology, knowing is a one-directional process in which the objects of knowing are subjected to the manipulative power of the knower. The article aims at discussing different perspectives in continental philosophy (Peter Berger's phenomenology, Mary Douglas's cultural anthropology, and the critical theories of Michel Foucault and Jürgen Habermas). Aspects of the contributions of Immanuel Kant, Friedrich Schleiermacher and Karl Barth, precursors in 'culture criticism', are also considered. It is shown that in recent postmodern thinking a symmetrical subject-subject schema replaces the subject-object schema. This position is enhanced by taking into consideration the emphasis in present-day historical Jesus research on the so-called 'alternative wisdom' of Jesus of Nazareth, which challenged the conventional wisdom of his day.
\end{abstract}

\section{WAT IS KULTUUR?}

Sedert die Tweede Wêreldoorlog is daar in akademiese kringe vanuit verskillende perspektiewe na die verskynsel kultuur gekyk. In die neo-Marxistiese tradisie, vanuit die perspektief van die historiese materialisme, is kultuur gesien as nie veel meer as 'n ideologiese sondebok nie. In ander kringe, vanuit die perspektief van die struktureelfunksionalisme, word kultuur gesien in terme van sosiale sisteme (instellings/strukture) wat konflikterend in interaksie met mekaar, gedurig ewewig soekend is. 'n Ander inte-

* Voordrag gelewer tydens die Voortgesette Teologiese Toerustingskursus van die Sentrum vir Teologiese Navorsing en Toerusting, Fakulteit Teologie (Afd A), Universiteit van Pretoria, 18-20 Junie en 11-14 November 1996. 
resse in kultuur, wat die perspektief van die simbolies-interaksionisme genoem word, is gefokus op die singewing van simbole, mites en rites in terme waarvan individue in die samelewing optree of gedetermineer word. Die sosiale sielkunde, weer, ondersoek innerlike waardesisteme, gesindhede en emosies van individue en sien só die psige as uiting van kultuur. Die studie van sosiale instellings is egter toenemend gefokus op die materiale basis van waaruit kollektiewe gedrag voortvloei en nie soseer op die meer abstrakte ideale, waardes, frustrasies of legitimasiesimbole van konflikterende belangegroepe nie. Wat die formele organisering van groepe betref, word die klem ook nie op die ondersoek na norme en ideale gelê nie, maar eerder op ekonomiese kragte en die uitwerking van die omgewing, die rol van of gebrek aan ondersteuningsbasisse, middele tot bemagtiging, fases van ontwikkeling en lewenssituasie-analises.

Dit is duidelik dat die vraag wat die studie van kultuur behels, uitermate gekompliseerd is. Is kultuur in hoofsaak die simboliese uitdrukking van menslike gedrag? Of is dit die waarneembare sosiale strukture wat deur die mens gevorm word? Of het dit met sowel die simboliese wêreld as die sosiale wêreld te doen? Hierdie vrae is gebaseer op die 'kulturele analise' soos aangebied in die werk onder outeurskap van $\mathrm{R}$ Wuthnow, $\mathrm{J}$ D Hunter, A Bergesen en E Kurzweil (1987).

Indien kultuur alleen simboliek sou wees, sal taligheid (Sprachlichkeit), seremoniële en rituele handelinge, ideologieë en religie gesien word as dié simbole in terme waarvan menslike gedrag beskryf en verduidelik kan word. So gesien, fokus die studie van kultuur op die simboliese rol wat kommunikasie, sosiale/religieuse seremonies (soos etes/eetgewoontes) en rituele (soos intronisasies, offermaaltye, nagmaal, inisiasies), ideologieë en godsdiens as identiteitsmerkers van groepe van mense vervul. Indien ons van só 'n definisie van kultuur sou uitgaan, het kultuur primêr met denke, ingesteldheid, emosie, waardes en lewens- en geloofspatrone op die abstrakte vlak te doen. Met ander woorde, kultuur is dan daardie dimensie wat oorbly nadat alle empiriese menslike gedrag opgeskort is - juis dit wat op 'n dialektiese wyse 'kultuur' veroorsaak én daaruit voortspruit! Kultuur is só gesien die dimensie wat bestaan uit die innerlike, onsigbare, teoreties-abstrakte aspekte van die mens - as individu én as die intersubjektiewe, kollektiewe persoonlikheid wat waardes gemeenskaplik met ander deel. Aspekte soos dit wat mense werklik doen en hoe hulle optree, die strukture en instellings wat mense vorm en die fisieke interaksie van mag en geld, word hiervolgens nie as 'kultuur' geag nie! Só 'n digotomie is die produk van die klassieke dualisme van Plato wat liggaam en gees van mekaar wil skei en gedurende die Moderne Era veroorsaak het dat kultuur met godsdiens verwar is en deur baie intellektueles in Europa geminag is. 
Karl Marx (1818-1883) het as 'jong-Hegeliaan'. hierdie dualisme betwis en steeds kultuur pejoratief gesien as 'n aspek van die 'superstruktuur' wat dialekties onderskei moet word van die waarneembare sosiale 'infrastruktuur' waardeur produksie en interaksie bemiddel word. Max Weber (1864-1920) het ook die klassieke digotomie betwis en aan kultuur groter positiewe belangrikheid verleen, hoewel hy dit steeds beperk het tot die sfeer van die 'geestelike moraliteit' wat te onderskei is van konkrete sosiale organisering in klas, staat en tegnologie. Emile Durkheim (1858-1917) beklemtoon die waarde van kultuur as gedeelde waardes, gevorm/misvorm deur 'numinieuse kragte' wat gereflekteer word in magsrelasies binne die samelewing. Talcott Parsons (19021979) bevind hom op dieselfde spoor wanneer hy die dialektiese onderskeid tref tussen die 'kulturele sisteem' (kollektiewe waardes) en die 'sosiale sisteem' (menslike interaksie). Die dialektiese sosiale wetenskap verdeel dus die wêreld van die mens in die (objektiewe) waarneembare sosiale wêreld en die (subjektiewe) denk- en ervaringswêreld.

In hierdie artikel word daarvan uitgegaan dat elke definisie van die begrip 'kultuur' relatief is tot 'n bepaalde tydperk, denkraamwerk en wetenskaplike invalshoek. Die definisie waarvan hier uitgegaan word, is dat kultuur gesien word as daardie onomlynde, moeilik waarneembare dimensie van menswees wat te doen het met denke, ingesteldheid, emosie, waardes en lewens- en geloofspatrone op die abstrakte vlak wat uitmond in menslike interaksie binne die raamwerk van kollektiewe strukture van ekonomiese, politieke, familiale en godsdienstige aard. Soos alle menise is Christene ook aan hierdie dialektiese kousaliteit gebind. Teologies gesien is dit 'n kwessie van 'skeppingsordeninge' in terme waarvan mense lewe en dit kan ook as 'natuurnoodwendigheid' geag word. Gelowiges is nie anders as ongelowiges hierby betrokke nie. Die verhouding waarin die mens tot kultuur staan, is dus in 'n sekere sin 'n kwessie van gedetermineerdheid of liewers 'n gebondenheid aan alledaagse lewenspatrone en situașies.

In die artikel word kortliks aandag gegee aan die werk van enkele sosiaal-wetenskaplikes/filosowe wat met hulle 'kultuurkritiek' invloed op resente teologie uitoefen.

\section{KULTUURKRITIEK WAT HEDENDAAGSE TEOLOGIE BEÏNVLOED}

Kultuurkritiek is die kritiese studie van kultuur wat die positiwistiese objek-subjek skema in die sosiale wetenskap teenstaan. In die positiwisme word die kenproses voorgestel as 'n eenrigtingverkeer vanaf die objek na die waarnemer toe. Kultuurkritiek is die produk van dialektiese/funksionele denke waarvolgens die objek en die subjek in 'n tweerigtingverkeer met mekaar verbind is. Gedurende die afgelope vyftig jaar was kultuurkritiek hoofsaaklik gerig op taligheid, simboliek, diskoers en die betekenis van die 
hermeneutiese proses. Volgens die werk van Wuthnow en ander (1987) word veral vier oriëntasierigtings in Europese fillosofie onderskei: fenomenologie, kulturele antropologie, strukturalisme en kritiese teorie. As eksponente van hierdie rigtings kan die name van Peter Berger, Mary Douglas, Michel Foucault en Jürgen Habermas genoem word.

\subsection{Oriëntasierigtings in hedendaagse filosofie}

Peter Berger (gebore in 1929 in Wenen en tans direkteur van die Boston University se navorsingsinstituut vir ekonomiese kultuur) is 'n eksponent van die fenomenologie. Hy staan krities in terme van die tradisie deurdat hy hierdie tradisie kontinueer en terselfdertyd afskeid neem van bepaalde aspekte van die denke van onder andere (die vroeëre) Heiddeger en Husserl. Berger reflekteer hoofsaaklik oor die ontologie (synskwessies) en die epistemologie (ken-kwessies). Hy gee veral aandag aan sake soos die hoogste waarheid, outentieke eksistensie en transendentele Dasein, en is daarom geïnteresseerd in godsdienssosiologie, die kerk en die teologie. Bekende werke van Berger is The social construction of reality (1967; uitgegee saam met sy student Thomas Luckmann as mede-outeur), The sacred canopy (1967), The heretical mind (1979) en The other side of God (1980).

Mary Douglas (gebore in 1929) is 'n eksponent van kulturele antropologie in die Britse tradisie en is tans direkteur van ' $n$ instituut vir navorsing oor kultuur in New York. Sy staan krities in die tradisie van Edward Evans-Pritchard and Edmund Leach se empiriese veldstudies van die sosiale funksies van die rituele en lewer kreatief bydraes met betrekking tot sosiale taboes, ostrasering en die rol van simbole, sosiale grense as identiteitsmerkers en -handhawing, en vergelykende kosmologieë. Sy bevind haar in die tradisie van Bronislaw Malinowski en Emile Durkheim se werk oor sosiale klassifikasiesisteme en die wyse wạarop samelewings hulleself handhaaf. Sy doen veral veldwerk in Zaïre (Belgiese Kongo). Bekende werke van haar is Purity and danger: An analysis of the concepts of pollution and taboo (1966), 'The meaning of myth' (1967), 'The social control of cognition" (1968), 'Heathen darkness, modern piety' (1970), 'The healing rite' (1970), Natural symbols (1970), The world of goods (1979; met Baron Isherwood as mede-outeur) en Risk and culture (1982; met Aaron Wildavsky as mede-outeur).

Michel Foucault (gebore in 1926 in Poitier, Frankryk) is beïnvloed deur die Marxistiese strukturalis, Louis Althusser, en ander 'Hegeliaanse' filosowe wat geïnteresseerd is in die geskiedenis van idees, die geskiedenis van mites, kuns en godsdiens. Foucault was aktief betrokke in die kommunistiese politiek, het aanvanklik die (teoretiese) filosofie verruil vir die (praktiese) sosiale wetenskap, het hom ook in die sielkunde be- 
kwaam, was betrokke in die praktyk van die psigiatrie, word die direkteur van die instituut vir filosofie in Clermont, Frankryk en sterf tragies in 1984. Sy belangstelling in die 'geskiedenis van idees' het aanleiding gegee tot publikasies oor die rol van taal in 'mentale' persepsies met betrekking tot onder andere nuttigheids- en waarde-oordele, rykdom en arbeid, en die wyse waarop die organisasie van spesifieke ruimtes en sosiale interaksie idees beïnvloed. Hy is veral geïnteresseerd in wat as die 'Ander' (l'Autrui) genoem word (kyk Beukes 1996b) - daardie aspekte van menslikheid wat deur die moderniteit as van minder of geen belang geag is nie: dit wat empiries nie rasioneel geken kan word nie, soos 'kultuur', die rol van taligheid, persepsie, innerlikheid; dit wat nie nuttigheidswaarde het nie, soos die 'mentale afwykende', die arme, die agtergeblewene.

Van Foucault se vroeëre werke (Engelse vertalings van oorspronklike Frans) wat konsekwensies vir kultuurkritiek bevat, is byvoorbeeld Madness and civilization: $A$ history of insanity in the age of reason (1961), The order of things: An archaeology of the human sciences (1966) en The archaeology of knowledge (1969). Sy latere werke konsentreer op die verskynsel 'mag' en hy is veral gëinteresseerd in die beïnvloeding van die veranderlikhede in mag op kennis en die wyse waarop kennisverkryging die aanwending van mag in sosiale strukture fasiliteer en verhoog. Hy sien nie mag noodwendig as negatief nie. 'n Aantal van sy werke oor hierdie tema is versamel in Power/ Knowledge (1980).

Jürgen Habermas (gebore in 1929 in Gummersbach, Duitsland), is die seun van 'n predikant, word intellektueel sterk beïnvloed deur die Nuremberg-verhore sedert 1945, studeer gedurende die jare 1949-1954 filosofie in Göttingen, doseer in Heidelberg en Frankfurt en is tans verbonde aan die Max Planck Instituut in Starnberg. Hy is 'n eksponent (saam met Max Horkeheimer, Theodore Adorno, Erich Fromm en Herbert Marcuse) van die Frankfurt Skool se dialekties-kritiese teorie. As student staan Habermas krities teenoor sy professore wat hulle doseerwerk voortsit asof daar geen wêreldoorlog plaasgevind het nie, hy neem Heidegger kwalik omdat hy nie Hitler se idees gerepudieer het nie en hy meen nie dat Marx (en Lukács) se insigte sonder meer direk in die naoorlogse situasie toegepas kan word nie. As dosent word hy bekend vir die teoretiese onderbou wat hy vir die studente-opstand van die sestigerjare verskaf het. Sedert die sewentigerjare is hy veral geïnteresseerd in die deursigtigmaking van die wyse waarop kennis in die samelewing aanleiding gee tot manipulasie, eskploitasie en asimmetriese interaksie. Hy het ten doel dat mense hulle eie sosiale omstandighede insien en op grond van selfrefleksie begin om hulle eie omstandighede te verander. Aanvanklik neem hy sy vertrekpunt in die dieptepsigologie van Freud en die kommunikasieteorie van Searle (kyk o a Klemm 1981; Van Aarde 1991). Sy latere werk oor 'kommunika- 
tiewe handeling' (kyk o a Volschenk \& Van Aarde 1994; Beukes 1996a:75-77) konsentreer op aspekte soos die kritiek op die 'instrumentele rede' van die klassieke objeksubjek skema. Habermas vervang hierdie skema met 'n 'intersubjektiewe' verhouding, sodat simmetrie in die sosiale handeling bewerk kan word. Van sy werke (Engelse vertalings waar oorspronklike Duits nie vir my beskikbaar is nie) wat besondere invloed uitgeoefen het, is Knowledge and human interests (1968), Toward a rational society: Student protest, science, and politics (1968-69), Legitimation crisis (1973), Communication and the evolution of society (1976), Theorie des kommunikativen Handelns: Handlungrationalität und gesellschaftliche Rationalisierung (2 Bande) (1981), Moralbewußtsein und kommunikatives Handeln (1983) en Der philosophische Diskurs der Moderne (1986).

Wat gemeenskaplik tussen Berger, Douglas, Foucault en Habermas is, is nie net die feit dat hulle almal belangrike invloed op die hedendaagse teologie uitoefen nie, maar ook (a) die feit dat hulle almal swaar gewig geplaas het op taligheid, klassesisteme en metaforisiteit - in kort: op kultuur, (b) dat hulle nie meen dat die sosiale wetenskap op die natuurwetenskap gemodelleer kan word nie (hierop word daar nie nou ingegaan nie), en (c) dat hulle die erfenis van die moderne kultuur bevraagteken, maar nie geheel en al daarvan kan wegbreek nie. Hierby kan ons byvoeg dat hulle almal ten diepste in die Kantiaanse paradigma beweeg en terseldertyd krities is ten opsigte van Immanuel Kant.

\subsection{Immanuel Kant}

Die filosofie van Immánuel Kant (1724-1804) het die na-oorlogse Duitse (en Nederlandse) teologie beslissend beïnvloed (kyk Barth [1952] 1972:266-312). So byvoorbeeld kan die dialektiese teologie van Karl Barth genoem word. Barth het krities in die Marburgse tradisie van die 'Kantiek' (Kant-Schleiermacher-Dilthey-Heidegger-Bultmann) gestaan (vgl Palmer 1969). Veral die Nuwe Hermeneutiek het op die voetspoor van Kant, Dilthey, Heidegger en Gadamer sterk klem gelê op taligheid as dié aspek van kulturele eksistensie.

In die lig van die doelwit van hierdie artikel word twee kwessies in verband met Kant en kultuurkritiek vervolgens kortliks hanteer. Dit is naamlik die probleem met betrekking tot vryheid en die rol van die kerk. Hierdie twee sake word bespreek as dinge wat met mekaar gemeen het. Wat Kant oor hierdie twee sake alles gesê het, word nie hier uiteengesit nie, behalwe die aanstip van enkele gedagtes. Wat die kwessie van vryheid betref, sal daar benewens Kant op 'n aspek van die insig van Friedrich Schleiermacher gefokus word en wat die rol van die kerk betref, op Karl Barth. Maar eers word 'n bietjie inligting oor die leefwêreld van Kant verskaf, sodat die probleem met betrekking tot vryheid en die rol van die kerk beter begryp kan word. 
Immanuel Kant lewe en werk in die tweede helfte van die agtiende eeu. Daar word dikwels na hierdie tydperk as die 'Moderne Era' verwys. Epistemologies word die moderniteit oorheers deur die 'instrumentele rede'. Dié rede kon nie meer aanvaar dat die transendentale steeds gesien word as dit wat in die logiese verlengstuk van die immanente, waarneembare wêreld lê nie. In die voor-moderne wêreld wat tot in die Bybelse tye strek, is God se teenwoordigheid in die wêreld van die mense - in die hede of in die toekoms - deur middel van mitiese spreke verwoord. Pre-eksistensie, eksistensie en post-eksistensie lê hiervolgens logies op dieselfde lyn. Na die Middeleeue, op grond van die invloed van onder andere die natuurwetenskap, het die rede van die mens die 'verwondering' van die numineuse (wat in die pre-eksistensie en die post-eksistensie gesetel is) toenemend laat afneem.

As filosoof het Kant onverpoosd daarna gestrewe om die sterrehemel en die mensewêreld só te orden dat alles hulle onderskeie plek het. So het God 'n plek en ook die kerk en die staat. Mense - ook kerkmense - is egter wesens van 'twee wêrelde'. Hulle is daarom vry om keuses uit te oefen wat pas by dié wêreld wat te onderskei is van die wêreld wat aan 'natuurnoodwendigheid' uitgelewer is. Soos alle mense is 'kerkmense' ook aan die natuurnoodwendigheid gebind. Vroeër in die onderhawige artikel is hierdie 'natuurnoodwendigheid' kultuur genoem. Die verhouding waarin die mens tot kultuur staan, is dus 'n kwessie van gedetermineerdheid, maar die 'sedelikgoeie' mens (die 'kerkmens') het die plig om van hierdie gebondenheid vry te wees. Die wese van die kerk is om die vryheid van kerkmense te fasiliteer sodat God onvoorwaardelik, vry van die binding aan die verganklikheid, gedien kan word. Maar is die mens waarlik vry? Die antwoord is nee! Kant het gevolglik 'n aanpassing gemaak. Iets wat tradisioneel nie by Kant herken word nie, maar wel deur die filosowe van ons dag wat in die Kantiaanse tradisie staan, is hierdie wending by Kant om in simboliek die weg te vind waar vryheid kan verwerklik (kyk Van Wyk 1995:527-532). Omdat die gebondenheid aan 'natuurnoodwendigheid' die mens die slaaf van determinisme maak en die keuse tot vryheid in die weg staan, beklemtoon Kant die rol van simboliek wat die 'goeie', vanuit die primaat van die intelligibele wêreld, in die sensibile wêreld vervul. Hierdie wending in die filosofie van Kant het nogal baie met sy siening van die rol van die kerk te doen.

Om saam te vat (vgl Friedrich [1949] 1977): In sy Kritik der reinen Vernunft (1781) het Kant die logiese positiwisme verwerp en sien, hy in dat objekte aan die kennende subjek verskyn na gelang van die vrae wat die subjek self wil vra. Hy onderskei tussen die wetenskaplike (sintuiglike) wêreld en die (nie-geobjektiveerde) wêreld waartoe die 'postulate' God, onsterflikheid en vryheid behoort. As deel van die sintuiglike wêreld is die mens aan natuurlike kousaliteit en sterflikheid gebonde, maar die 
mens is vry om die goeie te doen - nie ten einde (in mitologiese sin) hír en noú of láter in die 'onsterflike bedeling' beloon te word nie, maar omdat ons die plig en die vryheid daartoe het om die goeie ter wille van die goeie te doen. In sy Religion innerhalb der Grenzen der bloßen Vernunft (1793) sê hy dat die menslike natuur (vanweë die gebondenheid aan sterflikheid) egter op die handhawing van die self gerig is en dit kom op selfbevrediging neer en nie op die doen van die goeie ter wille van die goeie nie. Bekering tot die 'nuwe mens' wat vry is om onvoorwaardelik goed te doen, is daarom noodsaaklik. 'n Godsdiens wat op selfbevrediging gerig is (dit wil sê, op beloning), is vals en kom op bygeloof neer. Die 'geloof' wat die mens beveel om God onvoorwaardelik te dien, kom met gesag van buite die mens, is ' $n$ 'onveranderlike' geloof, berus op normatiewe geskrifte. [Oor die plek wat Kant in hierdie verband aan die Jesus van die geskiedenis gegee het, verdien vermelding en het 'n teoloog soos Schleiermacher sterk beïnvloed, maar ons gaan nie nou hierop in nie.] Hoewel Kant self nie in sy volwasse lewe 'n kerkganger was nie, het hy ingesien dat die kerk bestaan uit die gemeenskap van diegene wat vry is om God onvoorwaardelik te dien - 'n gemeenskap wat mekaar met betrekking tot hierdie 'kategoriese imperatief' bystaan. Die menslike natuur wat die bose aanhang, maak die bestaan en instandhouding van die kerk noodsaaklik, sodat die kerk daarop ingestel moet wees om sigself oorbodig te maak wanneer die sterflikheid in onsterflikheid oorgaan. Kultiese handelinge moet volgens hom simbole wees van die vrye wil wat God onvoorwaardelik dien. Die kerk is derhalwe dié plek waar simbole nie die mens sterker aan die natuurnoodwendigheid moet bind nie, maar vry moet maak om God onvoorwaardelik te dien. In my woorde sal dit daarop neerkom dat dit deel van die kerk se selfverstaan moet wees dat die plig om God te dien, paradoksaal van die mens vereis om vry van kultuur te wees en dat hierdie vryheid in ons (sintuiglike) wêreld alleen deur middel van simboliek verwerklik kan word. Grondmetafore in hierdie verband is myns insiens die geloof dat die kerk God se huishouding is, dat ons as kinders van God uit God gebore is, en dat ons uit die dood opgestaan het en derhalwe 'nuwe mense' is.

\subsection{Friedrich Schleiermacher}

Vervolgens word enkele gedagtes aangestip oor die wyse waarop Friedrich Schleiermacher (kyk Van Aarde 1995a; Mueller-Vollmer 1992:72-97), iemand wat Kant gelees en herlees het (Clements 1987:17, 50), en Karl Barth (kyk Van Aarde 1995b), iemand wat die twintigste eeu met sy 'Kantiek' in beroering gebring het, hulle uitspreek oor die mens se gebondenheid aan kultuur en die kerk se rol as fasiliteerder van die mens se vryheid om God onvoorwaardelik te dien. Maar eers word 'n baie kort oorsig van die lewe en werk van Schleiermacher gebied. 
Friedrich Daniel Ernst Schleiermacher is gebore op 21 November 1768 in Breslau en sterf op ses en sestigjarige ouderdom op 22 Februarie 1834 in Berlyn - volgens Leopold von Ranke het tussen twintig en dertig duisend mense die begrafnis bygewoon. Sy pa was ' $n$ kapelaan in die Pruisiese weermag. Hy begin sy formele teologiese opleiding by die Morawiese Kweekskool te Barby in 1785. Gedurende die periode 1787-1789 studeer hy aan die Universiteit van Halle en as gevolg van die invloed van die geleerdes F A Wolff en J S Semler maak hy hier kennis met die denkrigtings van die Aufklärung. Op grond van die filosofie van Immanuel Kant (1724-1804) begin hy worstel met die vraag hoe God 'wetenskaplik' geken kan word. Gedurende die periode 1796-1802 is hy predikant in die Charite-Hospitaal in Berlyn. Hy begin om hier 'n enorme invloed uit te oefen op die godsdienstige en intellektuele, kuns- en musiekgemeenkap van die Pruisiese hoofstad. In sy werk Über die Religion: Reden an die Gebildeten unter ihren Verächtern (1799) kritiseer hy skerp die 'godsdiensveragters'/"cultured despisers' onder die intelligentsia. Hy vertaal die Dialoë van Plato en dié vertaalprojek beïnvloed sy later hermeneutiese denke op 'n besondere wyse. In 1804 word hy aangestel as professor in die teologie aan die Universiteit van Halle. Hy doseer veral hermeneutiek, etiek en filosofiese dialektiek. Hy is veral entoesiasties oor die hermeneutiek en kan bestempel word as die vader van die hermeneutiek. Hy bly steeds as prediker aktief en bly sterk betrokke by kerklike belange. In 1805 publiseer hy die werkie, Weinachtsfeier: Ein Gespräch, wat handel oor die inkarnasie van Christus en dit bevat belangrike riglyne om sy belangrike dogmatiese werk Der christliche Glaube nach den Grundsatzen der evangelischen Kirche im Zusammenhänge dargestelt $(1821 / 2$ - 'n hersiene uitgawe verskyn in 1830) te verstaan. In 1806 val Napoleon Pruise in, verwoes Halle en gebruik die universiteitsgeboue as huisvesting vir soldate en diere. Schleiermacher begin die (Duitse) volk beskou as die wydste en omvattendste geloofsgemeenskap waaraan die individu kan behoort. Na die inname van Halle keer hy na Berlyn terug en word predikant van die bekende Triniteitskerk in Berlyn en preke wat hier gelewer word, word beroemd oor die hele Duitsland. Sy gepubliseerde preke bevat meer as een-derde van sy versamelde werke. In 1808 open die Universiteit van Berlyn. Schleiermacher word in 1810 aangestel as die dekaan van die teologiese fakulteit. In 1815 dien hy as rektor. Verwysings na Schleiermacher se werke het tot aan die begin van die tagtigerjare gekom uit die ou Sämmtlichen Werke wat in vele opsigte onvolledig en vir die meeste navorsers ontoegangklik is. Die nuwe projek Friedrich Schleiermacher Kritische Gesamtsausgabe word deur De Gruyter in Berlyn uitgegee en Band 1 ( 609 bladsye) het in 1984 verskyn en Band 7 (Teilband 1. beslaan 357 bladsye en Teilband 2 uit 409 bladsye) in 1980 en 1984 (Teilband 3 wat uit 672 bladsye beslaan). Hierdie Kritische Gesamtsausgabe word uitgegee onder redakteurskap van 
Hans-Joachim Birkner, Gerhard Ebeling, Hermann Fischer, Heinz Kimmerle en KurtVictor Selge. Dertien bande word beplan.

Schleiermacher was iemand wat in dialoog met sy tyd gestaan het - 'n tyd waarin die mensbeskouing dié was van goed, rasioneel en selfversorgend - en tog het hy nie die teologie in apologetiek laat opgaan nie. Hoewel hy gedagtepatrone van sy tyd oorgeneem het, het hy nie daarin versink nie. Taal is vir Schliermacher die medium van denke. Dit is ' $n$ individu wat taal gebruik, maar taal veronderstel gemeenskaplikheid, universaliteit. Enersyds skep taal onderskeidings as gevolg van individualisering en andersyds universaliseer taal in soverre dit gemeenskaplike taal is. Wesenlik deel van die proses van denke is die spanning wat daar tussen 'objekte' bestaan en denke in beweging bring. Daarom is, naas die 'ideaal van eenheid van denke', kontras, teenoorgesteldes, die posisie van die 'ander', deel van die proses van denke. Syn, identiteit, is in die proses van denke 'leeg' en word eers bepaal in 'gesprek met ander'. Die identiteit van syn word in gesprek bewerkstellig. Omdat daar in gesprek altyd beweeg word tussen identiteit en verskil en 'absolute kennis' onmoontlik is, omdat absolute identiteit vanweë die altyd teenwoordige teenstellings nooit bereik kan word nie, het kennis 'n 'onoorwinlike voorlopigheid'. Dialektiek is vir Schleiermacher die teorie oor die 'beginsels van die gesprek'. Gesprek word gemotiveer deur die moontlike 'eenheidwording' van gespreksgenote deurdat verskille opgehef word. Kommunikasie veronderstel die vervanging van vervreemdheid met vertroudheid, dit wil sê onkunde word met kennis vervang. Dialektiek gaan egter nie van die aanname uit dat 'absolute kennis' die ideaal van 'eenheid van denke' is nie, maar van 'n 'onoplosbare relatituiteit': 'alles is relasioneel tot alles'. Die ontkenning van 'absolute kennis' hoef egter nie tot skeptisisme aanleiding te gee nie.

Godsdienstige taal getuig van 'n gottglaubige Selbstbewußtsein. Die onmoontlikheid van 'absolute kennis' hou verband met die beperktheid van die mens, van die mens se eindigheid, van die mens se gebondenheid aan die geskiedenis. Hierdie beperktheid, die eindigheid/begrensdheid van die menslike subjek, kom neer op die feit dat die mens nie oneindig eksisteer nie, nie sigself kan skep nie en derhalwe die onmiddellike bewussyn van absolute afhanklikheid van beperktheid aanvoel - 'n gevoel van gebrek aan vryheid, ' $n$ uitgelewerdheid aan die geskiedenis. Die mens is bewus van sy/haar totale afhanklikheid. Selfbewussyn is die gevoel van volstrekte afhanklikheid. Die bewussyn ten opsigte van God (gottglaubige Selbstbewußtsein) is die strewe na vryheid, oneindigheid, verlossing en die verkryging daarvan lê buite die syn van die mensheid. In hierdie sin is die woord 'God' getuienis van die mens se eindigheid. Hier lê die oorsprong van die mens se mitiese en antropomorfe spreke oor God. Die 'onmiddellike bewussyn van die eindige self is die bewussyn van die mens as historiese 
objek wat alleen in taal en geskiedenis aanwesig is. Mitiese spreke oor God is die gevolg van die verskyning van God as 'n 'historiese objek', terwyl taal nie daarvoor voorsiening maak om God, wat geen objek is nie, tot 'taligheid' te bring nie: 'Von Allem, was vom höchsten Wesen ausgesagt werden kannen, paßt nichts recht, sondern alles bleibt bildlich ....'

Die woord Gefühl het algemeen voorgekom in die gesprekke van die sogenoemde 'intellektuele godsdiensveragters' van die negentiende eeu wat die 'instrumentele rede' met die estetika wou temper. Hierdie veragting van die godsdiens het na bewering voortgespruit uit 'n voortbou op die 'transendentale kritiek' van Kant - 'n bewering wat nie aan die Kantiaanse revolusie reg laat geskied nie! Kant beskryf die vermeende onbeperkte vermoë van Godskennis as 'dogmatisme' en as gevolg van die kombinasie van rede en waarneming ontken hy dat God deur abstrakte 'proposisies' geken kan word. Dit lei tot die insig in die dialektiese teologie dat God nie geobjektiveer kan word nie en tot die opvatting van die estetika dat selfverwesenliking in kuns en musiek gesoek moet word. Schleiermacher onderskei die begrippe 'gevoel' en 'emosie'. Laasgenoemde word deur die ontmoeting met objekte gewek, is derhalwe eindig, kortstondig en wisselend. 'Gevoel' is die bewussyn van eindigheid, is konstant en kom van buite die vermoë van die denkende en willende mens. 'Gevoel' is ' $n$ responderende ervaring. Vir Schleiermacher is teologie die refleksie op die mens se godsdienstige bewussyn, die gevoel van totale afhanklikheid wat nie 'n geobjektiveerde bewussyn is nie. 'Gottglaubige Bewußtsein' is 'n begrip wat beide op die eindige self en die oneindige God reflekteer en word altyd in 'n gegewe geloofsgemeenskap gelokaliseer. Die 'gevoel van absolute afhanklikheid' is 'n responderende ervaring binne die ekklesiale ruimte waar die kerugmatiese gebeure plaasvind.

\subsection{Karl Barth}

Oor die lewe en werk van Barth hoef daar in die kring van die Nederduitsch Hervormde Kerk nie baie gesê te word nie. Wat die tema 'kerk' en 'vryheid' met betrekking tot 'kultuurkritiek' betref, alleen die volgende (kyk Van Aarde 1995b):

Volgens Barth (1935:121) moet die kerk nie met die koninkryk van God verwar word nie. Die kerk is ook nie die keerkant van die koninkryk van God nie. Die kerk is wel menslik en daarom tydelik en ruimtelik. Ook die kerk is uitgelewer aan verganklikheid. Die eieaardigheid van die kerk as 'gemeenskap' moet gesien word as teenoor ander 'organisasies, plekke en gemeenskappe - soos die communio van die huwelik, familie, volk of staat', teenoor groeperings soos 'ras, kultuur en klas', teenoor 'verenigings en unies, alliansies en genootskappe'. Die vooronderstelling dat die kerk teenoor kulturele strukture staan, kom egter nie daarop neer dat die kerk die 


\section{Kultuurkritiek}

'teenstander' van hierdie gemeenskappe, organisasies en natuurlike groeperings is nie. Die lidmate van die kerk is natuurlikerwys daarvan deel, en konstitueer en vorm dit selfs - soos alle ander mense dit ook maar doen. Wat belangrik is, is dat die kerk as communio sanctorum nie 'staan of val by die vorme of doelstellings van enigeen van hierdie groeperings nie'. Die kerk word nie begrens deur hulle grense en identiteit nie en is ook nie betrokke by hulle on-derlinge konflikte nie. Die kerk se grense deurkruis en oorskry al hulle grense. Die kerk se belange val dus nie saam met die belange wat enigeen van hierdie groeperings adem nie - die kerk se belange is geheel en al anders as dié van natuurlike gemeenskappe en tegelykertyd is die kerk se belange op alle plekke en ten alle tye dieselfde - aldus my parafrasering van Barth.

\subsection{Voorlopige gevolgtrekking}

In die begin van die artikel is daarop gewys dat kultuur moeilik gedefinieer kan word. In die periode voor die Moderne Era het godsdiens en kultuur in mekaar se verlengstuk gelê en dit kon in die Jodedom gesien word in die feit dat die Jerusalemse tempel sentrum van die politiek, ekonomie en godsdiens was. Dit was as gevolg van Jesus van Nasaret se herdefiniëring van die konsep 'koninkryk van God' dat 'n spanning tussen kultuur en outentieke geloof in God opgeroep is. Paulus kontinueer hierdie tradisie (kyk Pelser 1996). In die Konstantynse paradigma was hierdie spanning nie werklik verwoord nie. Augustinus was 'n uitsondering. Eers met Luther se visie op vryheid en die kerk se plek teenoor die kultuur - 'n teruggryp na Jesus, Paulus en Augustinushet 'n verandering ingetree. Die natuurwetenskaplike paradigma het dit egter baie moeilik vir die mens gemaak om hierdie onderskeid te deurdink, te konkretiseer of te verbeeld. Die Kantiaanse revolusie het die dag weer laat breek. Schleiermacher was hiervan die ligdraer in die negentiende eeu en in die twintigste eeu was dit die dialektiese teologie se beklemtoning van die eksistensiale verstaan van geloofstaal. Denkers soos Peter Berger, Mary Douglas, Michel Foucault en Jürgen Habermas berei die kultuurkritiese denke met die oog op die een en twintigste eeu voor. Die teoloë moet derhalwe nie agterbly nie. Kant se visie op vryheid en die rol van die kerk is klassieke erfgoed. Schleiermacher (kyk ook Palmer 1969) kon dit vir sy tyd verwoord het en Barth en Bultmann vir hulle tyd. Wat van ons? Sekere klemtone in die postmodernisme ag die kerk as deel van die problematiek van die modernisme waarvan afskeid geneem moet word. Indien die kerk se selfverstaan egter gebaseer word op die wysheid van die historiese Jesus wat as 'n alternatief op die konvensionele eerste-eeuse wysheid gesien moet word, kan die kerk kultuurkrities én singewend die een en twintigste eeu ingaan. 


\section{DIE EERSTE-EEUSE KULTURELE WYSHEID EN DIE ALTERNATIEWE WYSHEID VAN DIE HISTORIESE JESUS}

In die Oud-Oosterse wysheidsliteratuur is die insig in die mens as kulturele wese in verhouding met God en medemens hokma (חָכדָמָה) noem. Wysheid is om harmonieus by God se skeppingsorde in te pas, wysheid is respek/vrees vir God en sy orde - 'n orde waar alles en almal hulle plek, tyd en rol het: 'n orde van eer en skande, 'n orde waar mans, vrouens en kinders hulle onderskeie regte en voorregte het, 'n orde van herkoms en geboorte, van Leviet en Israeliet, van Leviet, priester en Samaritaan, van besnedene en heiden, van heilig en onheilig, van rein en onrein; 'n orde waarvolgens daar in hierdie lewe (of, soos later gedink is, by dood of by die opstanding vanuit die dood) beloon of gestraf word. Hierdie wysheid toon 'n ontwikkelingstrajek in vorm en inhoud: van spreukagtige aforismes (bv die boek Spreuke) tot verhale (bv Job) tot diskoerse van opponerende gedagtes (bv Prediker); van gedragsreëls tot personifiërende taal, tot die identifikasie met die konsep 'wet van God'. Laasgenoemde, die sogenoemde 'Torawysheid' kom na vore in die Wysheid van Jesus, die seun van Sirag, die Wysheid van Salomo en laastens in die Rabbynse Fariseïsme se kulturele stratifikasie met betrekking tot mense, plekke en dinge ten opsigte van 'n hiërargiese klassifikasie in terme van heilig tot minder heilig, tot onheilig.

Navorsing deur veral Schmid $(1966,1968,1973)$ toon ooreenkoms in Oud-Oosterse wysheidsliteratuur (Egiptiese, Mesopotamiese en Israelitiese) met betrekking tot 'n bepaalde ontwikkelingstrajek. Aanvanklik is Wysheid geag as die 'krag' en 'beeld' van God in terme waarvan die wêreld pre-eksistent gestig en georden was. Later is Wysheid gepersonifeer en as één met God gereken. Toe kom die 'antropologiese' interpretasie van die Wysheid deurdat Wysheid die onderskeidingsprinsiep in sosio-religieuse etiek word tussen 'regverdig' (רציק) (רשע). Hierdie etiek hou verband met die Oud-Oosterse visie van 'n oog-om-oog, 'n daad-gevolg-samehang. Ten slotte het die Wysheid die vorm aangeneem van kritiese Wysheid gerig teen dié vergeldingsidee. Hierdie trajek kan verder gevoer word (kyk onderskeidelik Crenshaw $1981 \&$ Witherington 1994) deur ook wysheidspsalms $(19,62,94,37,73,49)$, die Wysheid van Jesus seun van Sirag, die Wysheid van Salomo, Barug 3-4 en 1 Esra 3-5 asook die Nuwe Testament in ag te neem. Dit was veral Ben-Sirag (ongeveer $180 \mathrm{v} \mathrm{C)}$ wat met behulp van die Mosaïese wet as goddelike wysheid die konvensionele wysheid se vergeldingsidee (hoewel uitgestel) in stand wou hou. Witherington (1994:115) wys daarop dat hoewel Spreuke 2:6, Ben-Sirag 1:9-10, 26; 6:37 en Wysh Sal 7:7; 9:4 Wysheid sien as 'n gawe van God, dit steeds alleen deur inspanning in terme van die daadgevolg-same-hang verkry kan word (Spreuke 4:10-27; 6:6, Ben-Sirag 4:17; 6:18-36 en Wysh Sal 1:5; 7:14). Verder is dit opvallend dat Joods-Hellenistiese literatuur soos Ben-Sirag 24:8-12 Wysheid as goddelike ordeningsprinsiep alleen met Israel geassosi- 
eerd sien (vgl ook Wysh Sal 10:1-21). Dit is eweneens in hierdie literatuur dat Wysheid met tora geidentifiseer word (Ben-Sirag 24:23; vgl ook Ben-Sirag 1:25-27; 6:37; 15:1; 19:20; 33: 2-3; Barug 4:1).

Postmoderne historiese Jesus-studies (kyk o a Borg 1994:18-43; Den Heyer 1996: 218-232) wys onder andere daarop dat die intensie van Jesus se wysheid neergekom het op kritiek ten opsigte van die heersende tempelideologie van die Jerusalemse owerhede en dat die sosio-historiese konteks daarvan dié van kontroversie met onder andere die Fariseërs was oor wat die 'wysheid van God' (kyk Borg 1995:88-142; Schüssler Fiorenza 1994) was. Hierdie kontroversie het met tora-wysheid te doen. Veral Matteus (maar ook ander skrywers, soos dié van die Hebreërbrief) het die aspek van (Christelike) tora-wysheid verder gevoer. Die 'vergoddeliking' van die na-Pase Jesus na analogie van die gnostiese verlossersmite toon ook raakpunte met die trajek in die wysheidsliteratuur dat Wysheid na die mensewêreld met 'n besliste missie gekom het (Spreuke 8:4, 31-36; Ben-Sirag 24:7, 12, 19-22; Wysh Sal 6:12-16; 7:22a, 27-28; 8:2-3, 7-9; 9: 10-16). In 1 Henog 42 is die uitspraak opvallend: 'Wysheid kon nie 'n plek vind om te vertoef nie, maar toe is ' $n$ plek in die hemel gevind. Daarna het Wysheid uitgegaan om by die mensekinders te gaan bly, maar sy kon nie 'n tuiste vind nie. So, sy het teruggekeer na haar eie plek en tussen die engele gewoon'. Ook die feit dat Wysh Sal 1:7; 9:17; 12:1 Wysheid met die Gees van God identifiseer, moet nie buite rekening gelaat word nie. Die Wysheid van Salomo kan gedateer word tussen middel-tweede en vroeg-eerste eeu v C (Clarke 1973:2).

Paulus het nie die historiese Jesus self geken nie en het ook nie noemenswaardig verwys na wat Jesus sou gesê of gedoen het nie. Tog is sy evangelie dat waaragtige lewe ' $n$ pneumatiese lewe op grond van genade is en nie 'n selfbevredigende lewe op grond van die 'werke van die wet' wat eer en wins orden in terme van verganklike kreatuurlikheid (soos herkoms en besnydenis) nie, indirek gebaseer op die tradisies oor die historiese Jesus. Hierdie tradisies het onder andere Markus die 'evangelie' genoem. 'n Belangrike komponent van hierdie tradisies is die feit dat Jesus 'n Geesvervulde wysheidsleraar en geneser was wat sy eie visie en belewenis van 'alternatiewe wysheid' deur middel van veral kernagtige simboliese spreuke, metaforiese vertellings, genesings en eksorsismes begin bekend maak het en in sy eie lewe waar gemaak het dat God se 'onbemiddelde' en 'paradoksale' teenwoordigheid hír en nóú (en nie alleen in die apokaliptiese sin dáár en later nie) manifesteer as 'n ontferming vir almal wat in die oë van selfgeregverdigdes niks is, niks het en niks jeens God en mens kan vergeld nie. Jesus het sodoende die koninkryk van God metafories herdefinieer in terme van 'n nie-hiërargiese, denkbeeldige huishouding waarin al die lede van dié familie op 'n gelyke wyse direkte toegang tot die Vader het en die Vader vir diesulkes wat weet hoe arm hulle voor God is, omgee, en waarin hulle as denkbeeldige broers en susters van mekaar in gehoorsaamheid aan die wil van die Vader vir mekaar sorg dra. Vanweë sy konsistente 
en onverskrokke onkonvensionele houding en optrede met betrekking tot veral die tempelideologie het Jesus met die Fariseërs in konflik gekom, is Hy deur Saddusese priesterhoofde en familiehoofde as ' $n$ bedreiging ervaar en deur die Romeinse prokurator, Pontius Pilatus, brutaal laat kruisig asof Hy 'n krimineel was (kyk Van Aarde 1996).

Die evangelie kan in die lig van die kernsake in bogenoemde historiese konstruksie van die historiese Jesus opgesom word met die woorde swakheid, skande en dwaasheid, maar wat paradoksaal God se krag - dinamiek - was waarmee Hy die mag van die sonde gebreek het, die mens met Hom versoen het en in die regte verhouding met Hom gestel het. Hierdie bevryding word dus beleef ten spyte van (en eintlik veral vanweë) die skandelike dood en geboorte van Jesus. Om saam met Jesus te sterf, is vir byvoorbeeld Paulus om saam met Hom te lewe - nou nie meer aan die sondemag onderdanig nie, want Hy is tot sonde gemaak sodat ons op grond van hierdie gebeure in die regte verhouding met God gestel kan word.

Die vorm en inhoud van Jesus se onderrig toon dat Hy ' $n$ wysheidsleraar was in terme van die ontwikkelingstrajek wat in die Oud-Oosterse wysheidsliteratuur te onderskei is. Sy leringe was mondeling van aard en het bestaan uit kort metaforiese vertellings (gelykenisse) en skerp 'een-lyn' aforismes. Die strekking in beide tipe vorms was 'skokkend' en het die hoorders uitgelok tot nuwe persepsies oor ou konvensionele kultuuropvattings. Laasgenoemde is voorgestel as onder andere die 'breë weg' teenoor die nuwe as die 'nou weg'. Die historiese Jesus se 'alternatiewe wysheid' het 'n gans andere voorstelling gebied as die konvensionele oor die rol van die kultus, oor wat rein en onrein is, oor Leviet, priester en Samaritaan, oor by wie God teenwoordig is, oor vrouens en kinders, heidene en uitgestotenes. Dit was in tweërlei opsigte nie heeltemal uniek nie: dit het aangesluit by enersyds die kritiek in die boeke Job en Prediker teen die 'vergeldingsdogma' van ' $n$ oog om ' $n$ oog, en by die personifikasie van die wet as wysheid soos ons dit in die wysheid van Jesus seun van Sirag en die Wysheid van Salomo aantref, en andersyds by die profetiese kritiek teen die onreg wat hooggeplaastes teen geringes pleeg. Dit was in tweërlei opsigte wel uniek deurdat dit enersyds die indirekte bemiddeling deur middel van die 'versoeningshandelinge' in die kultus deur die priesters en die offerritueel waardeur die mens in die regte verhouding met God gestel kon word, ontken het en andersyds die nasionale en patriargale voorkeure bevraagteken het. Dit was nie apokalipties van aard nie en het die moontlikheid van waaragtige lewe hír en nó́ verkondig.

\section{GEVOLGTREKKING}

In die pre-industriële, voor-moderne leefwêreld van die Bybel het godsdiens en kultuur in mekaar se verlengstuk gelê. 'n Voorbeeld van hierdie verskynsel is dat die Jerusalemse tempel in die voor-70 n C Jodedom sentrum van die politiek, ekonomie en godsdiens was. Dit was as gevolg van Jesus van Nasaret se herdefiniëring van die kon- 
sep 'koninkryk van God' dat 'n spanning tussen kultuur en outentieke geloof in God opgeroep is. Hiervolgens vra 'n lewe uit geloof, deur Paulus voorgestel as alleen deur die werk van die Gees van God moontlik, die verloëning van die self. Wat gevolg het op die historiese Jesus se aankondiging van die verwerkliking van God se 'koninkryk', is die geboorte van die kerk wat sedertdien begin het om voort te bestaan in die spanning van om 'in hierdie wêreld' te wees maar nie 'van hierdie wêreld' nie. Sedert die Konstantynse periode - toe kerk en wêreldse mag te gemaklik in 'n een tot een verhouding gesien is - het 'klerikales' hierdie spanning probeer verwerk deur praktyke soos die selibaat en die afsondering in abdye, weg van die 'leke'. Vroeg reeds in hierdie periode wou Augustinus ' $n$ uitsondering wees. Eers met Luther se visie op vryheid en sy tweerykeleer het ' $n$ verandering in visie ingetree wat as ' $n$ teruggryp na Jesus, Paulus en Augustinus gesien kan word. Die natuurwetenskaplike paradigma het te midde van industrialisasie en moderniteit dit egter baie moeilik vir die mens in die kerk gemaak om hierdie onderskeid te deurdink, te konkretiseer of te verbeeld. Die dialektiese teologie se beklemtoning van die eksistensiale verstaan van geloofstaal het in die laatnag van die moderne era die dag weer laat breek. Maar 'n eensydigheid in die hedendaagse kontekstuele teologie kan die pendule te ver laat swaai! Deur momenteel eksistensiële geloofsbeslissings te neem, is myns insiens die enigste wyse hoe die evangelie hiér en nóú geleef kan word.

\section{Literatuurverwysings}

Barth, K [1935] 1964. Credo: Die Hauptprobleme der Dogmatik dar gestellt im Ansschluß an das Apostolische Glaubensbekenntnis. 16 Vorlesungen, gehalfen an der Universität Utrecht im Februar und März 1935. Dritte Auflage. München: Chr Kaiser Verlag.

- [1952] 1972. Protestant theology in the nineteenth century: Its background \& history, translated by B Cozens \& J Bowden. London: SCM Press.

Beukes, C J 1996a. Anderbereddering: Met Adorno by die hartslag van die postmoderne intellek. HTS 52/1, 68-87.

- 1996b. Michel Foucault en die historisering van Anderswees. HTS 52/2\&3, 233-251.

Borg, M J 1994. Jesus in contemporary scholarship. Valley Forge, Pennsylvania: Trinity Press International.

— 1995. Als met nieuwe ogen: De historische Jezus en waar het op aan komt in het geloof van vandaag. Zoetermeer: Meinema.

Clarke, E G 1973. The Wisdom of Solomon. Cambridge: Cambridge University Press. (The Cambridge Bible Commentary.)

Clements, K W 1987. Friedrich Schleiermacher: Pioneer of modern theology. London: Collins Press. 
Crenshaw, J L-1981. Old Testament wisdom: An introduction. Atlanta: John Knox Press.

Den Heyer, C J 1996. Opnieuw: Wie is Jezus? Balans van is0 jaar onderzoek naar Jezus. Zoetermeer: Meinema.

Friedrich, C J [1949] 1977. The philosophy of Kant: Immanuel Kant's moral and political writings. New York: Random House. (The Modern Library.)

Klemm, D E 1981. Hermeneutical inquiry, Volume 2: The interpretation of existence. Atlanta: Scholars Press. (AAR Studies in Religion 44.)

Mueller-Volliner, K 1992. The hermeneutics reader: Texts of the German tradition from the Enlightenment to the present. New York: Continuum.

Palmer, R E 1969. Hermeneutics: Interpretation theory in Schleiermacher, Dilthey, Heidegger, and Gadamer. Evanston: Northwestern University Press. (Northwestern University Studies in Phenomenology \& Existential Philopsophy.)

Pelser, G M M 1996. Die verhouding kerk en wêreld/kultuur in die lig van die Pauliniese 'asof nie' ( $\dot{\omega} \varsigma \mu \dot{\eta})$. HTS 52/4, 715-733.

Schmid, H H 1966. Wezen und Geschichte der Weisheit. Berlin: Töpelmann.

—_ 1968. Gerechtigkeit als Weltordnung. Tübingen: Mohr-Siebeck.

— 1973. Schöpfung, Gerechtigkeit und Heil. ZThK 70, 1-19.

Schüssler Fiorenza, E 1994. Jesus - Miriam's child, Sophia's prophet: Critical issues in feminist christology. London: SCM.

Van Aarde, A G 1991. Die neo-Marxistiese interpretasie van Jürgen Habermas. Ongepubliseerde studiegids, Departement Nuwe-Testamentiese Wetenskap, Fakulteit Teologie (Afd A), Universiteit van Pretoria.

- 1995a.. Die hermeneutiese program van Friedrich Schleiermacher. Ongepubliseerde studiegids, Departement Nuwe-Testamentiese Wetenskap, Fakulteit Teologie (Afd A), Universiteit van Pretoria.

- 1995. h. Die menslikheid van en die verskeidenheid in die kerk. HTS 51/3, 865-875.

- 1996. Die historiese ondersoek na Jesus van Nasaret in perspektief. HTS 52/2 \& 3, 476-500.

Van Wyk, G M J 1995. Metafoor en waarheid. HTS 51/2, 517-538.

Volschenk, G J \& Van Aarde, A G 1994. Sistematies verwronge kommunikasie in Lukas 14:1-€: Die dialekties-kritiese teorie van Jürgen Habermas krities bespreek. HTS 50/3, 812-855.

Witherington, B 1994. Jesus the sage: The pilgrimage of wisdom. Minneapolis: Fortress.

Wuthnow, R, Hunter, J D, Bergesen, A \& Kurzweil, E 1987. Cultural analysis: The work of Peter Berger, Mary Douglas, Michel Foucault and Juergen Habermas. London/New York: Routledge \& Kegan Paul. 